\title{
Mood state effects on thought listing
}

\author{
HENRY C. ELLIS, PENNIE S. SEIBERT, and BEVERLY J. HERBERT \\ University of New Mexico, Albuquerque, New Mexico
}

\begin{abstract}
Using a thought-listing procedure, we investigated the kinds of thoughts experienced by individuals who have undergone experimental mood induction. The results of Experiment 1, in which neutral- and depressed-mood-induction groups were compared, showed that individuals who had received a depressed-mood induction rated significantly more of their thoughts as unfavorable. In Experiment 2, subjects were required to engage in a cognitive task before the thought-listing procedure; the experiment included an elated-mood-induction group, as well as neutral and depressed groups. Although effects were in the expected direction, no reliable differences were found among the three groups in the proportion of unfavorable thoughts listed.
\end{abstract}

This research addresses the issue of how emotional mood states affect the thoughts that an individual has while in a particular mood state and, in addition, while engaged in a cognitive task. A number of studies of emotional mood states have demonstrated that transient moods can affect memory and a variety of other cognitive processes. Representative of the range of empirical effects include mood and awareness (Hertel \& Hardin, in press), elaborative encoding (Ellis, Thomas, \& Rodriguez, 1984; Potts, Camp, \& Sturcke, in press), and state-dependent effects (Bower \& Mayer, 1989).

Prevalent in several theoretical accounts of the effects of mood states on memory is the idea that mood states produce a prevailing pattern of thoughts that, in turn, influence performance in a variety of cognitive tasks (e.g., Beck, Rush, Shaw, \& Emery, 1979; Ellis \& Ashbrook, 1988; Ingram, 1984). An explicit assumption in these theories has been that a depressed mood state may have its effect on memory and cognition by way of negative or unfavorable self-thoughts that interfere with performance on some cognitive task. Recent reviews (Ellis \& Ashbrook, 1989; Johnson \& Magaro, 1987) of the cognitionemotion literature reveal little direct investigation of the kinds of thoughts produced either by the production of transient mood states or by a person's prevailing mood states. Therefore, as a first step in understanding the possible relationship between mood states and their resultant thoughts, we conducted two experiments. In the first, we examined the effects of induction of a depressed mood on the production of unfavorable thoughts. In the second, we examined the effects of both depressed and elated moods on the production of unfavorable thoughts while subjects were engaged in an incidental memory task.

Ellis and Ashbrook (1988) have developed a resourceallocation model that can account for the effects of disruptive emotional states on memory and related cognitive processes. It is assumed that disruptive emotional states, such as a depressed mood, regulate the amount of capac-

Requests for reprints should be sent to Henry C. Ellis, Department of Psychology, University of New Mexico, Albuquerque, NM 87131. ity that can be deployed or allocated to a criterion task. When mood states are reasonably strong and the demands of the task are high, the interfering effects of the mood state will be greatest, because fewer resources are available and/or deployed for processing the task. An important means through which the allocation of resources may be mediated consists of the thoughts that are generated by a person's prevailing mood state. Negative self-thoughts stemming from a depressed mood can preempt resources that could otherwise be allocated to a criterion task.

In order to investigate the effects of depressed moods on the production of thoughts, we employed a thoughtlisting procedure that has been used in test-anxiety research (see Meichenbaum \& Butler, 1980). This procedure involves asking subjects to list thoughts that come to their minds while they are taking a test, and it has been adapted to our experimental situation. Accordingly, it is reasonable to assume that a thought-listing procedure can also be used to obtain a classification of thoughts that occur during emotional states such as being sad or happy and can meet some of the criteria suggested by Ericsson and Simon (1980) in studying verbal protocols.

\section{EXPERIMENT 1}

The purpose of Experiment 1 was to determine if subjects in an experimentally induced depressed mood would produce more unfavorable thoughts when asked to list them than would subjects in a neutral mood.

\footnotetext{
Method

Subjects and Design. Thirty-six volunteers from introductory psychology classes at the University of New Mexico served as subjects. They were randomly assigned to one of two mood-induction groups: neutral or depressed.

Mood induction and assessment. The Velten (1968) mood-induction procedure was employed to induce depressed and neutral moods. With this procedure, the subjects read statements that represent the mood being induced. Because previous research (Ellis, Thomas, McFarland, \& Lane, 1985; Sherwood, Schroeder, Abrami, \& Alden, 1981) has shown that it is not necessary to use all 60 statements to induce a mood, our subjects read every other statement from the original set at the rate of 1 every $20 \mathrm{sec}$. Following mood induction, the subjects were given a
} 
Depression Adjective Checklist (DACL) (Lubin, 1965) to assess the effectiveness of the mood induction.

Screening procedure. Initially, all subjects completed the Beck Depression Inventory (Beck et al., 1979) and were instructed to select the statements(s) that most accurately represented their feelings from the past week. Any subject who scored over 15 was excused from the experiment, thus minimizing the induction of a depressed mood in a subject who might already have been experiencing depressed feelings.

Procedure. The subjects were informed that they were free to stop participating in the experiment at any point. Following completion of the screening procedure, the appropriate mood was induced and then assessed through completion of the DACL. The subjects then engaged in a thought-listing procedure, which was accomplished by instructing the subjects to list all the thoughts that came to their minds while they were experiencing the mood induction; they had $2.5 \mathrm{~min}$ to complete this procedure. Following thought listing, the subjects were asked to rate each of their thoughts as being favorable or unfavorable, on a 5point scale ranging from "very favorable" to "very unfavorable." Upon completion of the experiment, the subjects were fully debriefed, and those who had received a depressed induction were given 10 statements to read from Velten's (1968) elated-mood induction to ensure that no subjects left the experiment feeling depressed.

\section{Results}

Success of mood-induction procedure. The moodinduction procedure was effective. The neutral-mood subjects scored an averge of 7.22 on the DACL, whereas the mean score for the depressed-mood subjects was 11.89 $[F(1,34)=4.94, p<.05]$.

Comparability of groups prior to mood induction. The average Beck Inventory score for subjects assigned to the neutral-mood condition was 6.28 , compared with 5.89 for the subjects assigned to the depressed-mood condition. These scores were not reliably different $[F(1,34)$ $=.06, p>.05]$, thus indicating that the groups were comparable before the mood-induction procedure.

Total number of thoughts listed. Subjects in the neutralmood condition produced an average of 6.83 thoughts, whereas subjects in the depressed-mood condition listed an average of $6.22[F(1,34)=.27, p>.05]$; the two groups were thus similar in total number of thoughts.

Proportion of unfavorable thoughts listed. The proportion of unfavorable thoughts listed was determined for each subject, by summing the number of thoughts rated by the subjects as being unfavorable or very unfavorable and dividing that sum by the total number of thoughts listed. The thoughts were rated by two independent raters who did not know to which condition the subjects had been assigned. Interrater agreement was essentially perfect. The two mood-induction groups differed reliably in the proportion of unfavorable thoughts they listed; the depressedmood subjects rated significantly more of their thoughts as unfavorable $(0.41)$ than did the subjects in the neutral condition, who had a mean proportion of 0.22 unfavorable thoughts $[F(1,34)=6.21, p<.05]$.

\section{EXPERIMENT 2}

The results of Experiment 1 establish the point that subjects who are given a depressed-mood induction do report more unfavorable thoughts than neutral-mood control subjects do. This finding is important, because it shows that the thought-listing procedure is sensitive to mood states and that the production of negative thoughts is one additional cognitive and/or judgmental outcome of moodinduction procedures.

Experiment 2 was conducted with two principal objectives: (1) to introduce an elated-mood induction, comparing the effects of elated, neutral, and depressed moods on the production of unfavorable thoughts, and (2) to evaluate the effects of these mood states on the reporting of unfavorable thoughts after subjects were given an incidental memory task. The issue is: Do unfavorable thoughts continue to be produced while subjects are engaged in a cognitive task, or, alternatively, is there a reduction in negative thoughts in the depressed-mood group relative to the neutral-mood control condition? In the latter case, there could be relatively fewer reports of unfavorable thoughts, because subjects are now engaged in a new task that places demands on cognitive activities, and, correspondingly, they might produce unfavorable thoughts at a level more comparable to that for neutral controls.

\section{Method}

Subjects and Design. Fifty-four volunteers from introductory psychology classes at the University of New Mexico served as subjects. They were randomly assigned to one of three mood conditions: depressed, elated, or neutral.

Mood induction and assessment. Mood induction was again accomplished through the use of the Velten (1968) procedure, with the addition of an elated-mood group. As in Experiment 1, only 30 statements from each induction were used. The DACL was used to assess the success of the mood-induction procedure.

Task sentences. The incidental memory task consisted of 10 sentences, each containing a target adjective, which were made distinct by a phrase that followed it in the sentence. For example, in the sentence "The hungry child opened the door of the refrigerator," the target adjective hungry is related to the phrase of the refrigerator. The sentences used in this study were similar to those used by Ellis et al. (1984, Experiment 1) in their elaborated sentence condition.

Procedure. The subjects followed the same procedure of screening, mood induction, and assessment that was described in Experiment 1. The subjects were then instructed to read 10 sentences and to rate each one on a 5-point comprehensibility scale that ranged from "very difficult" (1) to "very easy" (5). The sentences were presented in booklet form at a rate of $7 \mathrm{sec}$ each, and they served as an incidental memory task.

Following presentation of the sentences, the subjects worked on simple math problems for $1 \mathrm{~min}$. Next, in the cued recall task, the subjects were presented each sentence for $10 \mathrm{sec}$ with the target adjective missing, and they were instructed to recall the missing word.

Upon completion, the subjects listed their thoughts as described in Experiment 1 , with the difference that they were now instructed to list the thoughts that came to mind while they were reading and rating the sentences and while they were trying to recall the missing words. Thus, the thoughts provided by the subjects were to be those they experienced while performing the cognitive task, rather than while reading the mood-induction statements as in Experiment 1. The subjects then rated their thoughts as in Experiment 1, and an identical debriefing procedure was used.

\section{Results}

Success of mood-induction procedure. A significant mood-induction effect was obtained. The mean DACL scores of the groups were: elated, 4.94; neutral, 6.72; and depressed, $14.94[F(2,51)=16.97, p<.01]$.

Comparability of groups prior to mood induction. The average Beck Inventory scores for the elated (5.56), 
neutral (6.94), and depressed (6.50) groups were comparable $[F(2,51)=.64, p>.05]$.

Total number of thoughts listed. The average number of thoughts listed by the elated (7.10), neutral (5.94), and depressed (6.83) groups did not differ reliably $[F(2,51)=.89, p>.05]$.

Proportion of unfavorable thoughts listed. As in Experiment 1 , the proportion of unfavorable thoughts listed by each subject was determined by adding the number of thoughts rated as being unfavorable or very unfavorable and dividing that sum by the total number of thoughts listed. The proportion of unfavorable thoughts produced by the subjects in the three mood-induction conditions did not differ [elated, .31; neutral, .38; depressed, .41; $F(2,51)=.65, p>.05]$.

Type of thoughts reported. A categorization of the type of thoughts reported revealed that $97 \%$ of the thoughts listed pertained to the subjects' reactions to the sentence-rating task or to their attempts at recall of information-that is, to the cognitive task as distinct from their mood state. As a result, comparisons of thought listing across Experiments 1 and 2 are inappropriate.

\section{DISCUSSION}

The principal finding in Experiment 1 was that the thoughts listed by subjects after engaging in a moodinduction procedure were congruent with the mood being induced. Subjects who received a depressed-mood induction indicated that a higher proportion of the thoughts they experienced during the mood induction were unfavorable, compared with neutral-mood controls.

This is an important finding in two respects. First, it demonstrates that the Velten mood-induction procedure not only produces measurable changes in affect by way of the Depression Adjective Check List but also produces corresponding changes in unfavorable thoughts reported. These finidngs do not, however, allow us to conclude simply that changes in affect produce changes in thought or vice versa. Indeed, both changes may occur in parallel without either one mediating the other. The data are nevertheless consistent with the general view that depressed affective states can result from an individual's negative, unfavorable thoughts. Second, our findings also raise the possibility that a negative self-referent set, experimentally induced, may prevail while individuals engage in cognitive tasks.

The issue in Experiment 2 was: Do the mood effects on thought listing persist, as shown in Experiment 1, while subjects are engaged in the cognitive tasks of sentence rating or in the unexpected cued recall task? The results indicated that now the three mood groups did not differ reliably in the proportion of unfavorable thoughts listed.

There are, however, two aspects of this finding that should be noted. First, the trend of the thought-listing findings is in the direction that would be anticipated if it was expected that the mood states induced would persist in having an effect on thought listing during sentence rating and/or attempted recall. This is reflected in the largest proportion of unfavorable thoughts still being given by the depressed group and the smallest proportion being given by the elated group.

A second feature of Experiment 2 should be noted as well. Had reliable differences in mood effects on thought listing been obtained, it might have been argued that the effects were due, not to the cognitive processes associated with sentence rating and attempted recall, but rather to the delay in obtaining thought listings due to the interpolated tasks of sentence rating, math problems, and attempted recall. We point out, however, that this delay of approximately $4 \mathrm{~min}$ would have been insufficient to have accounted for such effects, on at least two grounds. First, Sherwood et al. (1981) have reported that the effects of a Velten mood induction persist for at least 20-30 min before any dissipation of the mood is evident. Second, Ellis et al. (1985) have noted that delayed recall of 15-25 min has not attenuated the effects of the induction of a depressed mood on recall.

In summary, we believe the use of thought listing as a procedure in investigations of cognition-emotion relationships to be a potentially promising approach. We are currently pursuing this line of research, using modified procedures to examine thought listing. These preliminary experiments provide evidence that reported thoughts are sensitive to induced mood states and leave open the issue of the influence of cognitive tasks on thought listing.

\section{REFERENCES}

Beck, A. T., Rush, A. J., Shaw, B. S., \& Emery, G. (1979). Cognitive therapy of depression. New York: Guilford.

BOWER, G. H., \& MAYER, J.D. (1989). In search of mood-dependent memory. In D. Kuiken (Ed.), Mood and memory: Theory, research, and applications. [Special issue]. Journal of Social Behavior \& Personality, 4(2), 121-156.

Ellis, H. C., \& AshBrooK, P. W. (1988). Resource allocation model of the effects of depressed mood states on memory. In K. Fiedler \& J. Forgas (Eds.), Affect, cognition, and social behavior (pp. 25-43). Toronto: Hogrefe.

Ellis, H. C., \& Ashrrook, P. W. (1989). The "state" of mood and memory research: A selective review. In D. Kuiken (Ed.), Mood and memory: Theory, research, and applications. [Special issue]. Journal of Social Behavior \& Personality, 4(2), 1-21.

Ellis, H. C., Thomas, R. L., McFarland, A. D., \& Lane, J. W. (1985). Emotional mood states and retrieval in episodic memory. Journal of Experimental Psychology: Learning, Memory, \& Cognition, 11, 363-370.

Ellis, H. C., Thomas, R. L., \& Rodriguez, I. A. (1984). Emotional mood states and memory: Elaborative encoding, semantic processing, and cognitive effort. Journal of Experimental Psychology: Learning, Memory, \& Cognition, 10, 470-482.

ERICSSON, K. A., \& Simon, H. A. (1980). Verbal reports as data. Psychological Review, 87, 215-251.

Hertel, P. T., \& Hardin, T. S. (in press). Remembering with and without awareness in a depressed mood: Evidence of deficits in initiative. Journal of Experimental Psychology: General.

INGRAM, R. E. (1984). Toward an information processing analysis of depression. Cognitive Therapy \& Research, 8, 443-478.

Johnson, M. H., \& MAGARo, P. A. (1987). Effects of mood and severity 
on memory processes in depression and mania. Psychological Bulletin, 101, 28-40.

LUBIN, B. (1965). Adjective checklists for measurement of depression. Archives of General Psychiatry, 12, 57-62.

Meichenbaum, D., \& Butler, L. (1980). Cognitive ethology: Assessing the streams of cognition and emotion. In K. R. Blankstein, P. Pliner, \& J. Polivy (Eds.), Advances in the study of communication and affect (Vol. 6, pp. 139-163). New York: Plenum.

Potrs, R., CAmp, C., \& Sturcke, C. (in press). The relationship be- tween naturally-occurring moods, elaborative encoding, and recall performance. Cognition \& Emotion.

Sherwood, G. G., Schroeder, K. G., Abrami, L. E., \& Alden, L. E. (1981). Self-referent versus nonself-referent statements in the induction of mood states. Cognitive Therapy \& Research, 5, 105-108.

Velten, E. (1968). A laboratory task for induction of mood states. Behavioral Research \& Therapy, 6, 473-482.

(Manuscript received August 24, 1989.) 